\title{
Novas tecnologias, políticas públicas e gestão do território escolar
}

RESUMO: Este estudo pretende refletir sobre as novas tecnologias incorporadas na escola. Considera tecnologia como sendo reflexo e resultado das demandas da sociedade (o professor e o educando em especial) e do modo de produção em que está inserida. Ao ressaltar o caráter de ferramenta das novas tecnologias, coloca o professor como figura insubstituível no processo de ensinar e aprender; e o estado como elemento-chave no processo de articulação entre sociedade e escola.

\section{New technology, public policy and management area school}

\footnotetext{
ABSTRACT: This study intends to discuss the new technologies incorporated in the school. Considers technology as a reflection and result of the demands of society (the teacher and student in particular) and the production method in which it operates. By noting the character of the new tool technologies, puts the teacher as an irreplaceable figure in the process of teaching and learning and the state as a key element in the process of articulation between school and society.
}

\section{Renato Pereira*}

* Licenciado em Geografia pela Universidade Estadual de Ponta Grossa (UEPG). Educador social na Associação Brasileira de Educação e Cultura (ABEC). Email: pgeographo@gmail.com

Palavras-chave:

NTIC;

Políticas públicas; Gestão do território escolar.

Key-words: NTIC; Public Policy; Management school. 


\section{Introdução}

As transformações em todos os cenários da sociedade globalizada, impulsionadas pelas novas tecnologias, difundidas de maneira síncrona mundialmente, andam a passos curtos pelas instituições da educação básica e, a inovação, conceito-chave no início deste milênio nem parece estar perto das escolas brasileiras. Assim, a sociedade do conhecimento, digital, não analógica e muito menos escrita a esferográfica vai se desenhando.

\footnotetext{
Como período e como crise, a época atual mostra-se, aliás, como coisa nova. Como período, as suas variáveis características instalam-se em toda parte e a tudo influenciam, direta ou indiretamente. Daí a denominação de globalização. Como crise, as mesmas variáveis construtoras do sistema estão continuamente chocando-se e exigindo novas definições e novos arranjos. Trata-se, porém, de uma crise persistente dentro de um período com características duradouras, mesmo se novos contornos aparecem. (SANTOS, 2000, p. 34).
}

Sem dúvida, a evolução da telemática', por conseguinte, das tecnologias de informação e comunicação, propiciaram a globalização da economia, da política, da cultura... e da educação, mas o giz e o quadro negro até hoje são as tecnologias mais utilizadas pelo professor.

Quando se fala em tecnologia é usual que se imagine computadores com multiprocessadores de última geração, pessoal especializado e um cabedal tecnológico altamente informatizado. Porém, sabe-se que a criação e a apropriação de técnicas fazem parte do desenvolvimento da humanidade. Mesmo em seus primórdios o homem inventa, inova, reinventa e renova.

1 Telemática pode ser entendida como o resultado da combinação entre os vários recursos das telecomunicações (telefonia, satélite) e a informática (computador), constituindo assim uma rede mundial (web), para processamento, armazenamento e transmissão de grandes volumes de informação em alta velocidade e definição.

2 Termo utilizado por David Harvey e Edgar Morin, para caracterizar as transformações ocorridas na sociedade, na economia, na ciência, na tecnologia... e na escola, no início do século XXI.

Geografia Ensino \& Pesquisa, v. 15, n.1, p. 97-110 jan./abr. 2011

Novas tecnologias, políticas públicas e gestão do território escolar

98 ISSN 2236- 4994

Ao fazer alusão à sociedade do início dos tempos históricos, Santos (1998, p. 18), ressalta que, "cada grupo humano construía seu espaço de vida com as técnicas que inventava para tirar do seu pedaço de natureza os elementos indispensáveis à sua própria sobrevivência. Organizando a produção, organizava a vida social e organizava o espaço, na medida de suas próprias forças, necessidades e desejos."

Mas, afinal, o que é tecnologia? Etimologicamente, o termo tem origem grega, com a junção dos termos techné (técnica ou arte) e logos (conjunto de saberes), porém a definição de tecnologia se amplia ao ser associada ao modo de produção vigente na sociedade.

Pode-se dizer que, das seculares técnicas, desde o uso do giz e do quadro negro até as emergentes e atuais tecnologias educacionais, percorreu-se uma longa trajetória evolutiva na organização didática do professor. Porém, o surgimento cada vez mais acelerado de novos meios tem trazido certa confusão na maneira de pensar o ensino, a escola e as políticas educacionais para este setor.

Milton Santos permite compreender melhor o período atual da história da humanidade ao caracterizá-lo como período técnico-científico-informacional. E, assim como em todas as épocas, sabe-se que, "o novo não é difundido de maneira generalizada e total. Mas os objetos técnicoinformacionais conhecem uma difusão mais generalizada e mais rápida do que as precedentes famílias de objetos. Por outro lado, sua presença, ainda que pontual, marca a totalidade do espaço" (SANTOS, 2000, p. 240).

Nesse cenário de incertezas ${ }^{2}$ estão as Novas Tecnologias de Informação e Comunicação (NTICs). Oriundas principalmente da Terceira Revolução Industrial, as novas tecnologias possibilitaram o advento do que se denomina "sociedade do conhecimento" ou "sociedade da informação". 
Para justificar o estudo, recorre-se a Velloso (2010), em sua pesquisa sobre financiamento da educação, quando ressalta a carência existente em pesquisas sobre a escola contemporânea, mormente a educação infantil e o ensino médio, necessitando-se de aproximação prudente e crítica às colaborações internacionais, "incorporando com maior vigor questões relativas à equidade e à eficiência no financiamento do ensino" (op cit., p. 16).

Sendo assim, este trabalho objetiva refletir sobre as novas tecnologias de comunicação e informação (NTICs) no ambiente escolar, considerando-as como reflexo do modo de produção vigente, assim como das relações entre políticas públicas, sociedade e escola. Ao se justificar a pesquisa pela presença cada vez mais acelerada desses novos meios - principalmente 0 computador e a internet - na vida cotidiana dos educandos, dos professores e da escola, indaga-se: qual a finalidade das novas tecnologias no ambiente escolar? Que interesses estão em jogo?

O avanço da ciência e da tecnologia não é tarefa de demônios, mas sim a expressão da criatividade humana [...] Quero saber a favor de quem, ou contra quem as máquinas estão postas em uso. Então, por aí, observamos o seguinte: não é a informática que pode responder. Uma pergunta política, que envolve uma direção ideológica, tem de ser respondida politicamente. Para mim os computadores são um negócio extraordinário. 0 problema é saber a serviço de quem eles entram na escola. (FREIRE, 1984, p. 6, grifo nosso).

\section{Tecnologia: aproximação conceitual}

Apropriar-se do vocábulo 'tecnologia' para expressar tão somente o produto decorrente da criatividade humana seria tão pueril quanto designar a expressão diabólica do ser, ou seja, a eterna dúvida existente entre a substituição do homem pela máquina ou a transformação da máquina em elemento auxiliar no modo de produção e na vida cotidiana das pessoas.

Devido a essa complexidade, poder-se-ia explicar o que não pode ser considerada tecnologia. Tecnologia não é um produto sem processo, muito menos um processo sem produto, pois tanto permeia o fazer técnico em benefício da humanidade, assim como contribui para a transformação da natureza enquanto produtora de exclusão na sociedade moderna.

Segundo Gama (1986, apud BRITO, 2006, p. 7), tecnologia:

[...] não é um conjunto de técnicas ou de todas as técnicas, e nem é uma sofisticação da técnica. A passagem da técnica para a tecnologia (e esta não exclui a primeira) não é a questão da gradação ou desenvolvimento interno ao campo das técnicas: é a questão que se refere à formação socioeconômica em que se realiza. [...] Não é o conjunto de invenções ou qualquer uma delas individualmente. $O$ avião não é uma tecnologia, como não é o rádio, o radar ou a televisão, muito embora seja esta a acepção mais difundida em marketing.

Por assim dizer, a tecnologia é também o resultado do momento em que é desenvolvida, pois é reflexo do modo de produção vigente na sociedade, que prima pela acumulação de capital, se tornando cada vez mais instantânea, competitiva e perversa.

Geografia Ensino \& Pesquisa, v. 15, n.1, p. 97-110, jan./abr. 2011

Renato Pereira 
Em consequência disso, na sociedade globalizada, se tornou mais explícita a diferenciação entre os que têm acesso, os que buscam uma aproximação e os que estão totalmente alheios às inovações. Para Schaff (1995, p. 47), isso pode produzir uma

[...] nova divisão entre as pessoas, a saber: uma divisão entre as que têm algo que é socialmente importante e as que não têm. Este algo, no caso, é a informação no sentido mais amplo do termo que, em certas condições, pode substituir a propriedade dos meios de produção como fator discriminante da nova divisão social, uma divisão semelhante, mas não idêntica, à atual subdivisão em classes.

0 que se percebe é que esse fluido rizomático se entrelaça entre seletos grupos, demonstrando a negação do que seja a própria globalização, o que dá seus contornos de perversidade. Resultado disso é o 'pensamento linear' da sociedade, que rotula a tecnologia, compreendendo-a somente como um produto, pois se deixa sistematicamente desacompanhar do processo acelerado com que a técnica evolui.

Para Milton Santos (2000), a globalização apresenta-se em dois processos paralelos: de um lado, através da infraestrutura, ou seja, as condições materiais e de outro, as relações sociais entre países, classes e pessoas. 0 autor revela ainda que, essa nova situação se alicerça em dois pilares, de um lado o dinheiro e de outro, a informação.

Tecnologia e técnica sempre se entrelaçam e se confundem. Também não se trata da techné grega, em que se traduzia na arte do bem-fazer, pois Vargas (1994) ressalta que a techné se apoiava na resolução de questões práticas e na tentativa de guiar as pessoas em problemas vitais como cura de doenças, constituindo em conhecimentos e habilidades que eram transmitidos de geração a geração. Porém, para Morin (2005), do ponto de vista epistemológico, é impossível isolar a noção de tecnologia ou techné pela existência de uma relação cíclica que percorre as várias instâncias, da ciência à técnica, da técnica à indústria, da indústria à sociedade, da sociedade à ciência etc.

Bueno $(1999$, p. 87) ao considerar que a tecnologia se apropria de dois tipos de culturas - a científica e a técnica -, busca conceituar tecnologia como sendo

[...] um processo contínuo através do qual a humanidade molda, modifica e gera a sua qualidade de vida. Há uma constante necessidade do ser humano de criar, a sua capacidade de interagir com a natureza, produzindo instrumentos desde os mais primitivos até os mais modernos, utilizandose de um conhecimento científico para aplicar a técnica e modificar, melhorar, aprimorar os produtos oriundos do processo de interação deste com a natureza e com os demais seres humanos.

O grau de parentesco entre a técnica e a ciência, considerando que esta última, na maioria das vezes, funda-se na busca de soluções para problemas existentes na sociedade também revela a importância da tecnologia. Para Sancho (2001) e Brito (2006), a tecnologia pode ser dividida em três grandes grupos:

* Tecnologias físicas: os instrumentos ou equipamentos, ou seja, o giz, o quadro negro, a carteira, o livro, os computadores, os satélites;

* Tecnologias organizativas: refere-se à forma como as pessoas interagem e se relacionam

Geografia Ensino \& Pesquisa, v. 15, n.1, p. 97-110 jan./abr. 2011

Novas tecnologias, políticas públicas e gestão do território escolar 100 ISSN 2236- 4994 com o mundo, em âmbito orgânico, buscando novas formas de reengenharia. A internet enquanto rede mundial se encaixa nesta categoria.

* Tecnologias simbólicas: pode ser entendida como a forma de comunicação entre as pessoas, da escrita à fala, são as interfaces de comunicação, os símbolos utilizados que abrangem tanto as tecnologias físicas quanto as organizativas.

Por entender que essa classificação remonta a processos que em determinados 
momentos estão interligados e ao mesmo tempo tendem a ser dissociados é que se tenta compreender a finalidade das novas tecnologias na escola. Favoráveis, contrários ou temerários estão os professores quanto ao uso dessa parafernália no ensino.

Nesse sentido, por mais que se desgaste o teorizar sobre esse novo paradigma, importante pensar a educação nesse contexto e, mais importante, o ensino, neste limiar de século XXI. Se por um lado o modelo de escola é considerado obsoleto, o professor não deve ser rotulado a essa premissa, pois seu pensar crítico possibilita que novas técnicas sejam apreendidas. Por enquanto, tecnologias são incorporadas e políticas públicas são instauradas.

\section{Novas tecnologias no ensino: Estado do Paraná}

Segundo Moraes (1997), a década de 1970 marca as primeiras iniciativas de uso da informática no ensino no Brasil. Em 1971, em seminário promovido pela USP de São Carlos em parceria com uma universidade norte-americana, iniciou-se a discussão sobre o uso de computadores no ensino de Física; e, em 1973, no Rio de Janeiro, a I Conferência Nacional de Tecnologia Aplicada ao Ensino Superior registra as primeiras demonstrações do uso do computador em atividades de ensino, ainda que na modalidade CAl ${ }^{3}$ (Instrução Assistida por Computador).

Se a década de 1970 marca as primeiras iniciativas do uso da informática no ensino no Brasil, nos anos oitenta essas demandas são efetivadas através das primeiras políticas públicas voltadas a disseminação das novas tecnologias. 0 estado do Paraná acompanha 0 caminhar nacional e, de acordo com Quarelii (2004, apud BELINE, 2006), esse processo se desenvolve de duas maneiras: de um lado com professores que percorriam os estados da região sul do país apresentando seminários e projetos e, de outro, através do PRONINFE, com a implantação do Centro de Informática na Educação (CIEd) em Maringá, em 1988.

Com laboratórios implantados em todo o país e o encaminhamento para uma cultura de uso das novas tecnologias não só no trabalho pedagógico do professor, mas em todo o ambiente escolar, é na década de 1990 que esse processo sofre grande expansão. Com ação efetiva no estado do Paraná, o PROINFO 4 se constitui no principal programa.

Instaurado pela Portaria MEC $n^{0}$ 522, de 9 de abril de 1997, o PROINFO é um programa educacional criado com a finalidade de promoção do uso pedagógico das tecnologias de informação e comunicação nas redes públicas de educação básica, sendo suas ações desenvolvidas sob a responsabilidade da SEED/MEC, em articulação com secretarias de educação dos estados e dos municípios. No Paraná, a adesão ao Programa ocorreu no primeiro semestre de 1997, ficando estruturado junto à Secretaria de Estado da Educação (SEED/PR).

Para tanto, o Ministério da Educação, no seu papel de coordenador das políticas nacionais de educação traçou, dentre outras, diretrizes de fortalecimento da ação pedagógica do professor em sala de aula e da gestão da escola, assim como, apontou para a implementação de políticas de modernização, com a introdução de inovações tecnológicas no processo de ensino-aprendizagem. O Programa apresenta ainda a intenção de melhorar a qualidade do processo de ensino-aprendizagem através da criação de uma nova organização nos ambientes escolares mediante a incorporação adequada das novas tecnologias (BRASIL, 1997a).
3 Essa tecnologia começou a ser pesquisada principalmente na Europa e nos Estados Unidos na década de 1970 e adotava procedimentos de tipo tutorial e exercícios de fixação. Atualmente, parte desse modelo é incorporada no desenvolvimento de sistemas ICAI (Instrução Inteligente Auxiliada por Computador), constituindo a base do modelo não-presencial de ensino mediado por TICs, conhecido como eLearning.

${ }^{4}$ Em sua proposta original tinha 0 nome de Programa Nacional de Informática na Educação. Porém, por meio do Decreto 6.300/2007 passa a se chamar Programa Nacional de Tecnologia Educacional.

Geografia Ensino \& Pesquisa, v. 15, n.1, p. 97-110, jan./abr. 2011

Renato Pereira 
Neste intuito também é criado o Centro de Experimentação em Tecnologia Educacional CETE, destinado primordialmente a facilitar a evolução do conjunto de ações do PROINFO, estabelecendo uma infraestrutura de comunicações e experimentação que integrasse MEC, NTEs, escolas, fornecedores e demais parceiros do Programa (BRASIL, 1999).

Das estratégias do PROINFO, pode-se destacar o desenvolvimento de infraestrutura de suporte técnico de informática no sistema de ensino público e o estimulo à interligação de computadores nas escolas, para possibilitar a formação de uma ampla rede de comunicações vinculada à educação (BRASIL, 1997a).

Em 2004, cada Núcleo Regional de Educação (NTE) passou a sediar uma Coordenação Regional de Tecnologia na Educação (CRTE). Atualmente, a Secretaria de Estado da Educação conta com 32 CRTEs, que atuam nos mesmos municípios de abrangência dos Núcleos Regionais de Educação (NRE).

Junto a esse novo pensamento em relação à escola e o ensino, ocorre verdadeira descentralização das atividades dos NTEs. Das formações continuadas passou-se à realização de assessorias aos professores nas escolas. No Paraná, as CRTEs agora contam com profissionais responsáveis por assessorar os professores in loco. Esses agentes, antes multiplicadores, neste momento são denominados assessores de tecnologia em educação, divididos em duas categorias: assessores técnicos e assessores pedagógicos.

A constituição da equipe de assessores pedagógicos para cada CRTE é feita de acordo com 0 número de escolas, bem como o de municípios de abrangência de cada Núcleo Regional. Em Ponta Grossa, estado do Paraná, sede no NRE, a equipe é composta por dois assessores técnicos e dez assessores pedagógicos.

As 111 (cento e onze) escolas estaduais de ensino regular, somadas as escolas de ensino especial, resultam em aproximadamente doze escolas para cada assessor. Os assessores pedagógicos da CRTE-PG atendem aos municípios de Carambeí, Castro, Imbituva, Ipiranga, Ivaí, Palmeira, Piraí do Sul, Ponta Grossa, Porto Amazonas, São João do Triunfo e Tibagi, mesma abrangência do Núcleo Regional de Educação de Ponta Grossa (NRE-PG).

Geografia Ensino \& Pesquisa, v. 15, n.1, p. $97-110$ jan./abr. 2011

Novas tecnologias, politicas públicas e gestão do território escolar

Cartograma 1 - CRTE/NRE Ponta Grossa - municípios de abrangência (2010). 
Podem ser assessores técnicos tanto professores do quadro próprio quanto técnicos lotados na Secretaria de Estado da Educação. Esses profissionais são responsáveis pelo assessoramento para a implantação, manutenção dos equipamentos e suporte aos usuários dos laboratórios de informática dos CRTE.

Os assessores pedagógicos são professores pertencentes ao quadro próprio do magistério que tenham atuado por no mínimo dois anos em sala de aula. São responsáveis pelo desenvolvimento de ações de cunho gerencial de programas, formações continuadas e de conteúdos mediados por novas tecnologias. Para aprofundamento do estudo e maior entendimento sobre o papel do assessor pedagógico, foi realizada entrevista com um desses profissionais da CRTE-PG, que neste trabalho será identificado somente como Assessor Pedagógico.

O que mais se evidencia como função principal do assessor pedagógico é a assessoria aos professores de maneira individual in loco nas escolas. Porém, o entrevistado assevera que o retorno maior está no trabalho com grupo de professores. 0 assessor pedagógico deixa claro que o planejamento é um aspecto de grande relevância para que os professores não só tenham acesso, mas utilizem as novas tecnologias em seu trabalho pedagógico.

Diante disso, parece haver, por parte desse profissional, preocupação quanto à continuidade das ações, pois, na realidade, os programas se constituem em políticas de governo, o que se transforma em um dos maiores empecilhos para o uso efetivo de novas tecnologias no trabalho pedagógico do professor.

Procuramos atendê-los em horários e dias diversos, previamente agendado com a escola, para que a assessoria atinja o maior número possível de professores. Todos os tutoriais elaborados pela CRTE ficam disponíveis no site do NRE para que os professores possam consultá-los caso encontrem dificuldades no uso dos multimeios. Além disso os administradores locais são orientados a disponibilizarem, no laboratório de informática da sua escola, uma cópia impressa desses tutoriais para consulta. Nossa aproximação junto aos professores permite que eles sintam-se bem em nos telefonar caso precisem de ajuda. 0 correio eletrônico também é outro aliado. (Assessor Pedagógico).

Ao fazer alusão ao uso, por professores e educandos, do laboratório de informática, presente em todas as escolas do município de Ponta Grossa, ressalta que

[...] é de comum acordo que apresentem a equipe pedagógica da escola, como utilizarão o espaço mediante um projeto ou planejamento. Depois de submetido a apreciação para possíveis ajustes poderão agendar o dia e horário de uso. Muitas escolas já contemplam o uso das novas tecnologias em seus Projetos Político-Pedagógicos (PPPs), o que demonstra que além da prática também há uma ação reflexiva sobre o uso. (Assessor Pedagógico).

Diante das mais variadas dificuldades dos professores quanto ao uso das novas tecnologias, o que muitas das vezes está relacionada ao pouco ou nenhum acesso a esses meios em sua vida cotidiana, fica implícita na fala do assessor que o tempo de serviço do professor também é determinante na aceitação de novas ferramentas pedagógicas. Segundo ele, existe uma discrepância entre o profissional recém-formado que está na escola e o que está caminhando para o final de carreira docente. Porém,

Geografia Ensino \& Pesquisa, v. 15, n.1, p. 97-110, jan./abr. 2011

Renato Pereira 
Os mais jovens demonstram dificuldades de acesso por não possuírem equipamento próprio ou conexão à Internet. Outros podem apresentar certo receio de estragar o equipamento ou ainda porque não querem expor aquilo que imaginam ser uma fragilidade. [Ao serem apresentados às novas ferramentas], sentem-se mais motivados para fazer uso. (Assessor Pedagógico).

Pela fala do assessor, essa dificuldade está tanto no planejamento quanto no desenvolvimento da aula por parte do professor. Por outro lado, acrescenta ainda que, 0 principal fator que favorece o uso das novas tecnologias no ensino é o

[...] barateamento na aquisição [do equipamento] somado a expansão do software livre. A desfronteirização de tempo e espaço proporcionada pela Internet é outro fator importante na sedução ao uso. Estamos imersos num mundo tecnológico. (Assessor Pedagógico)

Os assessores pedagógicos também são responsáveis pelo auxílio aos professores na elaboração de objetos de aprendizagem ${ }^{5}$, posteriormente publicados na web, através do Portal Dia-a-dia Educação.

\begin{abstract}
A orientação dada na assessoria é sobre a inserção do material no ambiente. As questões conceituais e/ou de conteúdo disciplinar, caso o professor tenha alguma dúvida, fica sob a orientação da equipe disciplinar do NRE. Contudo, o número de objetos publicados poderia ser maior, mas o que temos que comemorar é que esses números estão crescendo e a qualidade dos trabalhos também. (Assessor Pedagógico).
\end{abstract}

Contrária às premissas do modo de produção vigente, porém aliado às novas tendências, as redes (Internet), ao se constituírem em rizomas, trazem o conceito de colaboraçãa $0^{6}$, o que faz com que as informações fiquem mais acessíveis.

5 Denominação dada aos materiais didáticos do Portal Dia-a-dia Educação, disponibilizado em: $<\quad$ http:/l www.diaadiaeducacao.pr.gov.br >.

6 Neste caso, colaboração é 0 modo com que os usuários da Internet interferem na produção e/ou disseminação de materiais que serão disponibilizados na rede mundial de computadores, a Internet. É uma forma de inteligência coletiva (LÉVY, 1999).

Geografia Ensino \& Pesquisa, v. 15, n.1, p. 97-110 jan./abr. 2011

Novas tecnologias, politicas públicas e gestão do território escolar

\title{
Novas tecnologias e gestão do território
}

Segundo Francisco Chagas Fernandes, Secretário da Educação Básica (SEB/MEC) do 'governo Lula', o Brasil conta com três fontes de financiamento para o setor educacional:

* recursos vinculados constitucionalmente (representando parcela mais significativa);

* salário-educação;

* empréstimos internacionais, constituindo reforço necessário e de grande importância na composição dos investimentos em educação.

De acordo com Corrêa (1995, p. 83),

A gestão do território constitui o conjunto de práticas visando, no plano imediato, à criação e ao controle de uma dada organização espacial, isto é, as formas espaciais, suas funções e sua distribuição no espaço. Visa também ao controle dos processos que afetam a organização espacial, entre eles a concentração e a dispersão das atividades no espaço. Em última instância a gestão do território, uma faceta da gestão econômica, política e social, constitui um poderoso meio através do qual se viabiliza a reprodução da sociedade como um todo. (grifo nosso). 
E acrescenta,

[...] como fato social a gestão do território é caracterizada por uma historicidade definida a cada momento por agentes e práticas distintas. $\mathrm{Na}$ fase atual do capitalismo as grandes corporações multifuncionais e multilocalizadas e o Estado são, efetivamente, os principais agentes da gestão do território. (ibid., p. 83, grifo nosso).

Dados da Secretaria de Estado da Educação (SEED-PR) apontam que foram instalados laboratórios de informática com acesso a internet em todas as unidades escolares de ensino fundamental e médio do estado; TVs-Multimídia (conhecida no meio escolar por "TVpendrive") em todas as salas de aula; assim como a manutenção de uma equipe de assessores pedagógicos para orientação aos professores no tocante ao trabalho com as ferramentas utilizadas, principalmente o computador $e$ a internet.

Em relação ao uso do laboratório de informática, ao se comparar os dados disponibilizados pelo Paraná Digital, através da PRDEstatística ${ }^{7}$, entre 2007 e 2010, houve um crescimento acelerado no número de horas em que são usados os computadores nas escolas da rede estadual de ensino do Núcleo Regional de Educação de Ponta Grossa (NRE-PG). Esse fenômeno pode ser explicado se for considerado:

a) 0 aumento no número de computadores com acesso à internet (de oito laboratórios de informática monitorados no mês de junho de 2007, passou-se a 106 em outubro de 2010);

b) a atuação das Coordenações Regionais de Tecnologia na Educação (CRTEs), através dos assessores técnicos e pedagógicos;

c) a aceitação, por grande parte dos professores, às novas tecnologias, principalmente 0 computador e a internet;

d) o envolvimento da gestão escolar na manutenção dos equipamentos e no incentivo aos professores quanto ao uso de novos recursos pedagógicos; e,

e) a atuação estatal de forma efetiva com a implantação de diversos programas.

Merece atenção o baixo número de acesso em setembro de 2009 (Gráfico 1), devido ao recesso escolar forçado pelo alarde provocado pela gripe H1N1. Fora esse fato isolado, a cada ano vem aumentando significativamente o número de horas em que professores e educandos fazem uso dessa ferramenta.

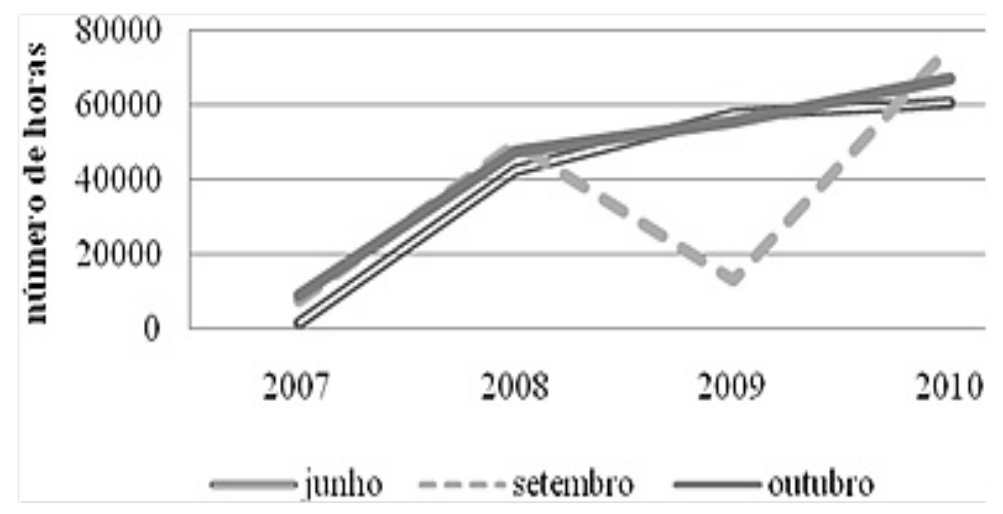

7 Em 2007 ocorre o início do monitoramento de uso dos computadores dos laboratórios de informática pela PRDEstatística. 0 relatório por regional encontra-se disponivel em: http://www.prdestatistica.seed.pr.go v.br/ >. Acesso em: 20 out. 2010.

Geografia Ensino \& Pesquisa, v. 15, n.1, p. 97-110, jan./abr. 2011

Gráfico 1 - Total de horas de acesso aos computadores dos laboratórios de informática (NRE-PG, 2010). 
A partir disso, pode-se considerar que, na atualidade, essas tecnologias se tornaram agente hegemônico nas políticas de estado e de governos e atuam ativamente na regulação de programas voltados à educação, já que são reflexo das mudanças no mundo do trabalho $\mathrm{e}$, além disso, permeiam a sociedade em geral, em especial o que foi e o que venha a ser a escola, do presente e do futuro.

\section{Em vez de concluir, "que tal" continuar refletindo sobre as novas tecnologias: o professor como elemento insubstituível no processo ensino-aprendizagem}

Além de serem resultados das demandas da sociedade e do perfil do aluno contemporâneo, as tecnologias incorporadas no meio educacional, devem atender as necessidades do professor. Porém, pensar esse profissional como um dos principais agentes do ensino e da aprendizagem é o desafio em questão. Por isso, pode-se dizer que, na atualidade, usar as novas tecnologias se torna imprescindível. Ao perceber a aceitação por parcela significativa dos professores, pode-se dizer que as novas tecnologias estão 'ganhando espaço'8 tanto na vida cotidiana, quanto na escola e nas salas de aula.

${ }^{8}$ Os gráficos 2 e 3 são resultado de pesquisa realizada com professores da rede estadual de ensino de Ponta Grossa, Paraná, sobre 0 uso de novas tecnologias no ensino. Usa-se o termo 'ganhando espaço' pelo grande número de professores que ainda sentem dificuldades no desenvolvimento de seu trabalho pedagógico com o uso de novas ferramentas.

Geografia Ensino \& Pesquisa, v. 15, n.1, p. 97-110 jan./abr. 2011

Novas tecnologias, politicas públicas e gestão do território escolar

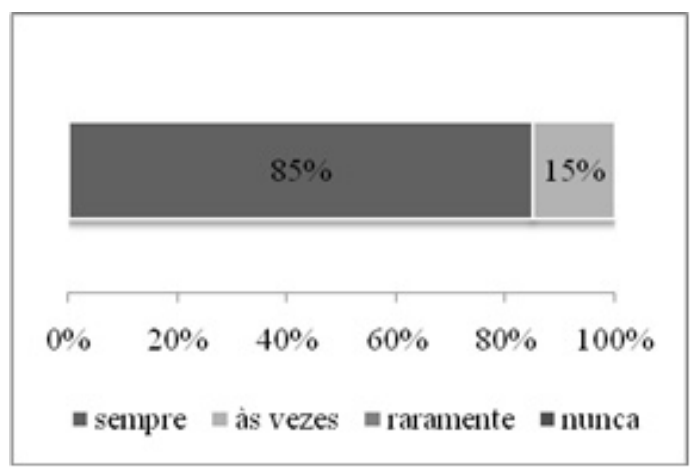

Gráfico 2 - Uso do computador no planejamento das aulas

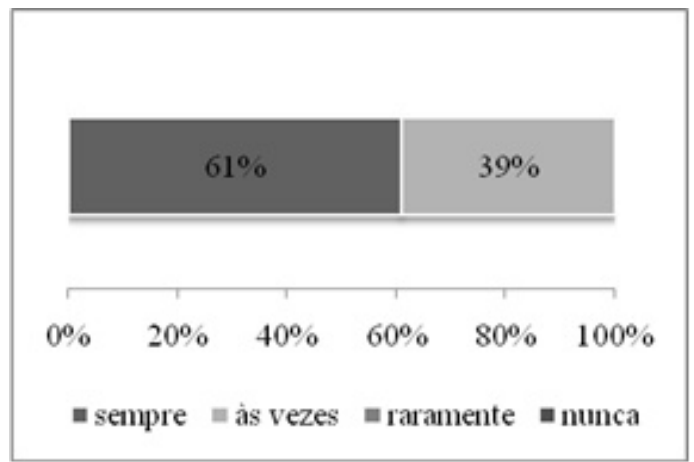

Gráfico 3 - Uso de novas tecnologias em sala de aula

Moran (2000) salienta que o professor, com o uso das novas tecnologias em sala de aula pode se tornar um orientador do processo de aprendizagem. Porém, é preciso que esse profissional reconheça sua importância no processo de ensinar e aprender, buscando atualizar-se constantemente. Não se trata do profissional que saiba fazer uso do computador, navegar na web ou utilizar o e-mail, mas daquele que utilize esses recursos para atingir seus objetivos de ensino. 


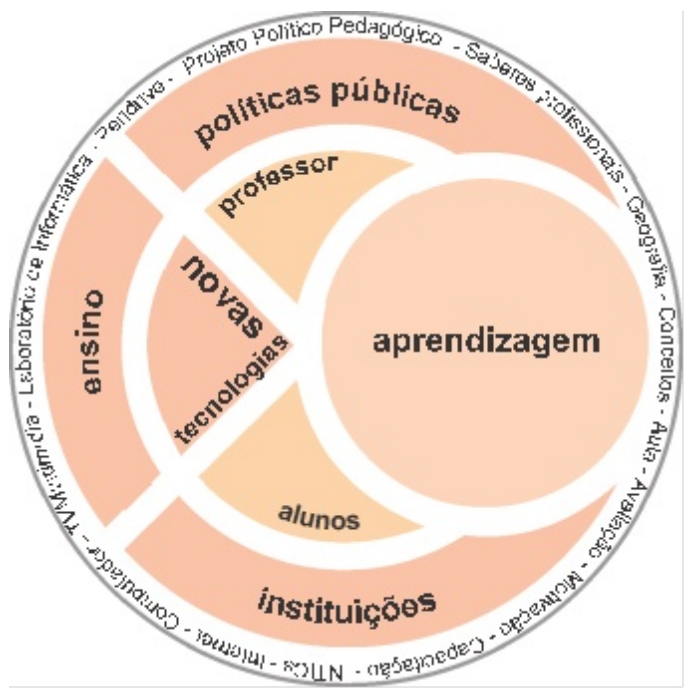

Figura 1 - Novas tecnologias na escola. Org.: Pereira (2010)

Como visto, não são as novas tecnologias que irão resolver as defasagens na aprendizagem. Porém, distanciar essas ferramentas da realidade do professor, pode promover a perpetuação da intolerância ao novo, o descaso à tentativa de novas metodologias e, ainda, pode comprometer a esperada formação continuada do docente.

Litwin (2001, p. 18) afirma que, "[...] adaptar-se aos desenvolvimentos tecnológicos resulta na capacidade para identificar e pôr em prática novas atividades cognitivas, pois as tecnologias vão gerando permanentemente possibilidades diferentes: daí sua condição particular de ferramenta".

É preciso que o professor não se sucumba aos interesses excludentes da globalização, que em todo ramo profissional prima pela objetividade, velocidade e fluidez, sendo necessário que se reconheça esse profissional como figura insubstituível no processo de ensinoaprendizagem, enquanto sujeito crítico frente ao modo de produção.

Fazer uso de novas tecnologias não significa excluir as tradicionais, mas possibilitar uma maior aproximação à temporalidade dos alunos. Não se pensa mais um mundo não-plugado. Não se imagina o futuro sem a utilização da informática. Por conseguinte, não se concebe mais uma escola fora da realidade informacional, muito menos um professor temeroso frente a esses novos desafios.

Por isso, é também papel do Estado, além de prover o professor de novas ferramentas, propiciar que o profissional domine essas tecnologias, do giz ao computador. Desse modo, certamente, facilitará a formação de um profissional consciente de sua atuação na sociedade, no seu trabalho e, principalmente, no seu objetivo pedagógico: o ensino.

\section{REFERÊNCIAS}

BELINE, W. Contradições emergentes entre proposta e implementação da informática na educação paranaense: análise das falas dos assessores pedagógicos. Dissertação (Mestrado em Ensino de Ciências e Educação Matemática) - Universidade Estadual de Londrina, 2006, Londrina, 2006.

Geografia Ensino \& Pesquisa, v. 15, n.1, p. 97-110 jan./abr. 2011

Renato Pereira 
BRASIL. Ministério da Educação e Cultura. III plano setorial de educação, cultura e desporto; 1980/1985. 2. ed. Brasília: MEC, 1982.

Conselho de Segurança Nacional. Secretaria Especial de Informática. Comunicado SEI/SS $n^{0}$ $\overline{015 / 83}$, de 23 de agosto de 1983. Diário Oficial da União, Brasília, 29 ago. 1983.

Ministério da Educação. Relatório de 1989. Brasília: MEC, 1989.

Ministério da Educação e do Desporto. Secretaria de Educação Média e Tecnológica. Programa Nacional de Informática Educativa - PRONINFE. Brasília: MEC/SEMTEC, 1994.

Lei n. 9.394, de 20 de dezembro de 1996. Estabelece as diretrizes e bases da educação nacional. Diário Oficial da União, Brasília, 23 dez. 1996.

. Ministério da Educação e do Desporto. Secretaria de Educação a Distância. Programa Nacional de Informática na Educação - Prolnfo: diretrizes. Brasília: MEC/SEED, 1997a.

Ministério da Educação. Portaria n 522, de 9 de abril de 1997. Cria o Programa Nacional de Informática na Educação - Prolnfo. Brasília, 1997b.

Ministério da Educação. Secretaria de Educação a Distância. Programa Nacional de Informática na Educação. Projeto de implementação do CETE. Brasília: MEC/SEED, 1999.

. Ministério da Educação. Plano Nacional de Educação - PNE. Brasília: MEC/lnep, 2001.

Ministério da Educação. Parecer CNE/CEB n 41/2002, aprovado em 2 de dezembro 2002. Institui Diretrizes Curriculares Nacionais para a Educação a Distância na Educação de Jovens e Adultos e para a Educação Básica na etapa do Ensino Médio. Brasília: MEC, 2002.

Decreto $n^{0} 6.300$, de 12 de dezembro de 2007. Dispõe sobre o Programa Nacional de Tecnologia Educacional - Prolnfo. Brasília, 2007.

BRITO, G. S. Inclusão digital do profissional professor: entendendo o conceito de tecnologia. In: ENCONTRO ANUAL DAANPOCS, 30., Anais... 2006.

BUENO, N. L. O desafio da formação do educador para o ensino fundamental no contexto da educação tecnológica. Dissertação (Programa de Pós-Graduação em Tecnologia) - Centro Federal de Educação Tecnológica do Paraná, Curitiba, 1999.

CHIMIN JUNIOR, A. B. Jogos de estratégia de computador: hipertextualizando a Geografia. Trabalho de Conclusão de Curso (Bacharelado em Geografia) - Universidade Estadual de Ponta Grossa, 2005.

CORREAA, R. L. Identificação dos centros de gestão do território no Brasil. R. bras. Geogr., Rio de Janeiro, v. 57, n. 1, p. 83-102, jan./mar. 1995.

FREIRE, P. A máquina está a serviço de quem? Revista Bits, maio 1984.

HARVEY, D. Condição pós-moderna. São Paulo: Loyola, 2003.

LITWIN, E. Educação a distância: temas para o debate de uma nova agenda educativa. Porto Alegre: Artmed, 2001.

MORAES, M. C. Informática educativa no Brasil: uma história vivida, algumas lições aprendidas. Revista Brasileira de Informática na Educação, n. 1, 1997.

MORIN, E. Ciência com consciência. 8. ed. rev. Rio de Janeiro: Bertrand Brasil, 2005.

O método 3. Porto Alegre: Sulina, 1999.

Geografia Ensino \& Pesquisa, v. 15, n.1, p. 97-110 jan./abr. 2011

Novas tecnologias, politicas públicas e gestão do território escolar 108 ISSN 2236- 4994
PARANÁ. Secretaria de Estado da Educação. Superintendência de Estado da Educação. Instrução n. 04/2004. Curitiba: SEED/SUED, 2004a.

Secretaria de Estado da Educação. Resolução 1636/2004. Cria a Coordenação Estadual de Tecnologia na Educação - CETE. Curitiba: SEED/SUED, 2004b. 
Secretaria de Estado da Educação. Superintendência de Estado da Educação. Diretoria de Tecnologia Educacional. Orientações gerais e encaminhamentos às Coordenações Regionais de Tecnologia - CRTEs. Curitiba: SEED/SUED/DITEC, 2008a.

Projeto Paraná Digital: manual do usuário, versão 2.0. Curitiba: SEED/C3SL, 2008b.

Secretaria de Estado da Educação. Superintendência de Estado da Educação. Diretoria de Tecnologia Educacional. Coordenação Estadual do Proinfo. Orientações ao Programa Proinfo Integrado/MEC. Curitiba: SEED, 2009.

Núcleo Regional de Educação de Ponta Grossa. Ações da CRTE. Disponível em: < http://www.nre.seed.pr.gov.br/pontagrossal >. Acesso em: 10 jul. 2010a. 2010b.

Paraná digital. Disponível em: < http://www.diaadiaeducacao.pr.gov.br/ / >. Acesso em: 12 jul.

PRDEstatística. Disponível em: < http://www.prdestatistica.seed.pr.gov.br >. Acesso em: 20 out. 2010.

SANCHO, J. M. (Org.) Para uma tecnologia educacional. Porto Alegre: Artmed, 2001.

SANTOS, M. Técnica, espaço, tempo: globalização e meio técnico-científico informacional 4. ed. São Paulo: HUCITEC, 1998. 2000.

Por uma outra globalização: do pensamento único à consciência universal. São Paulo: Record,

SCHAFF, A. A sociedade informática: as conseqüências sociais da segunda revolução industrial. 4. ed. São Paulo: Brasiliense, 1995.

VELLOSO, J. Pesquisas no país sobre o financiamento da educação: onde estamos? (2010). Disponível em: < http://www.inep.gov.br/ >. Acesso em: 5 nov. 2010.

\section{Correspondência}

Renato Pereira - Rua João Kubinski, 240. CEP. 84073-040 - Ponta Grossa - PR. Brasil

E- mail: pgeographo@gmail.com

Recebido em 07 de dezembro de 2010.

Revisado pelo autor em 23 de fevereiro de 2011.

Aprovado em 14 de abril de 2011.

Geografia Ensino \& Pesquisa, v. 15, n.1, p. 97-110 